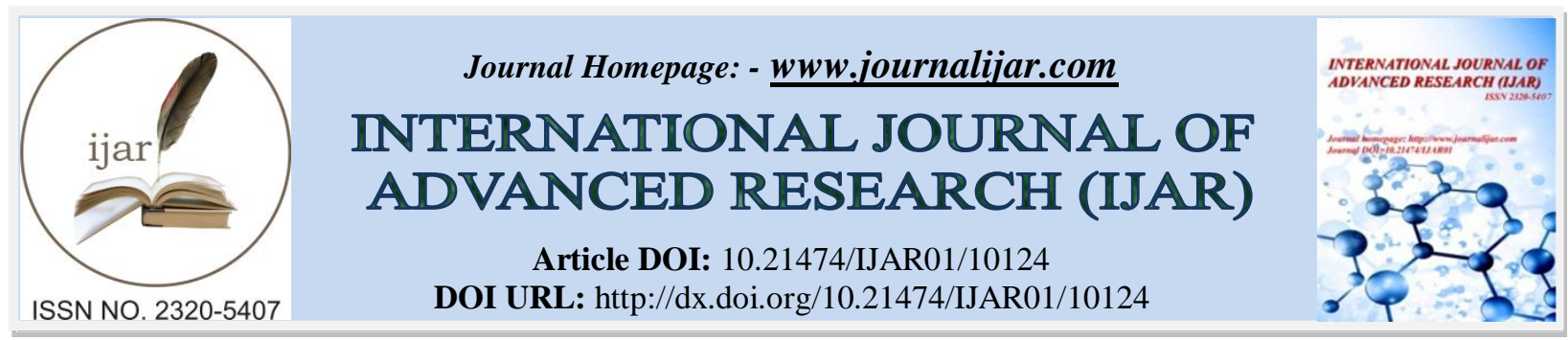

RESEARCH ARTICLE

\title{
KNOWLEDGE, ATTITUDE AND PRACTICE REGARDING BIOMEDICAL WASTE AMONG DENTAL STUDENTS AND HOUSE SURGEONS.
}

\section{Samreen Mazhar ${ }^{1}$, Asghar Ali ${ }^{1}$, Mahwish Bano ${ }^{2}$, Raza Abbas ${ }^{2}$, Mir Hussain Sultani ${ }^{3}$, Samar Gul ${ }^{3}$ and M. Tahir ${ }^{3}$.}

1. BDS, MPH, Assistant Professor, Baqai Dental College, Baqai Medical University, Karachi.

2. BDS, MPH, Professor, Baqai Dental College, Baqai Medical University, Karachi.

3. BDS, House surgeon, Baqai Dental College, Baqai Medical University, Karachi.

\section{Manuscript Info}

…………………

Manuscript History

Received: 01 October 2019

Final Accepted: 03 November 2019

Published: December 2019

Key words:-

Knowledge, Attitude, Biomedical Waste.

\section{Abstract}

This cross-sectional study was conducted in private dental college undergraduate students and house surgeons of Karachi Pakistan. The duration of study was six months and Convenience sampling technique was used. The close ended questionnaire were distributed and filled by these study participants including third year, final year students and trainee house surgeons. The management of biomedical waste is one of the biggest challenges of the present day regarding human health. Regarding the awareness program 10-25\% health care waste can cause severe health issues and the purpose of this study was to find out the knowledge, attitude and practice regarding biomedical waste management regarding undergraduate dental students and house officers.

A total of 150 BDS students, third and final year as well as house surgeons were included, 55 students from 3rd year, 68 students from final year and 27 house surgeon (1.81 mean, 2.459 std. deviation) that this included 88 male and 66 female participants (mean of 1.44 and std. deviation of 0.498 ). The $60.7 \%$ person's had a good response about the biomedical waste should be segregated into different categories too most of the respondents gave no answer about the segregation of waste management is $39.3 \%$. The $53.3 \%$ participants concerning the biomedical waste management should fulfilled a part of curriculum at undergraduate level; At the end of this study showed that information and awareness level regarding BMWM of study participant was not sufficient and there was a significant difference in practice and management about the biomedical waste management amongst different studies.

Copy Right, IJAR, 2019,. All rights reserved.

\section{Introduction:-}

According to Indian Government rules of handling for Biomedical Waste Management, it has been defined as the quite a lot of wastes that are generated during finding, management, inoculation of individuals, natural world and in the research activities pertaining there to or else in the manufacture or testing of biologicals". (1)

Corresponding Author:-Samreen Mazhar.

Address:-BDS, MPH, Assistant Professor, Baqai Dental College, Baqai Medical University, Karachi. 
There were a various ranges of health care services with variety of huge broad-spectrum and professional hospital to minor urban dispensaries including are encompassed by the health care sector. These facilities are significant segment of our society for the reduction of health problems and to eliminate health harms to the people. In the progression of health harms, health care sector produce a large number of biomedical wastes curing which could be dangerous for those who get in touch with these medical wastes. (2)

According to the BMW, health services waste management is especially unusual from house hold and industrial devastate management. Nowadays management of biomedical waste is one of the important challenges related to the human health. ${ }^{(3)}$

The problem of waste has been managed, recently in increase in developing countries anywhere there is small history of the completion of formal and informal group of people as well as educational awareness program has been arranged in a community and it is predictable that $10-25 \%$ of the healthcare waste generated is hazardous \& causes severe health problem ${ }^{(4)}$

While the patients think about the activities are established in a healthcare environment formed which had been the possible to negative effect of human beings and atmosphere. Mostly these wastes include bandages, hypodermic needles, syringes, soiled cotton, tubing such as intravenous sets as well as urinary catheters etc and this waste is frequently called as biomedical waste, worldwide it is also known as a variety of other names such as medical waste, clinical waste and health care waste. It constitutes currently $15 \%$ to $25 \%$ taken as a whole waste produced in a hospital, the remaining waste such as wrapping of drugs, waste paper, cardboard as well as available food etc. However according to "world health organization", states that $85 \%$ of hospital wastes are fundamentally safe; where the $10 \%$ are contagious and $5 \%$ are non-infectious other than they were included in hazardous wastes. Regarding 15 to 35 percent of hospital waste is synchronized as communicable waste. There were a variety is dependent on the entire quantity of waste was generated. ${ }^{(5)}$

Regarding the international stage $16-84 \%$ of the hospitals did not fix to the norms of biomedical waste management. The majority of the healthcare employees had unsatisfactory practices with respect to biomedical waste management in India. (6)

Hospital waste is infectious and hazardous and there was a big problem was rising in medical field. On the other hand, in research studies this important issue had been restricted, and there was a grave need of information on this matter for planning and policy decision in the future. It was vital to point out for a number of reasons and there was a substantial doubt around this estimation, further research and data were needed to obtain a consistent picture of this condition. ${ }^{(7-8)}$

Along with an increase in the number of hospitals and their inherited Biomedical Waste (BMW), a huge bulk of it is dumped unprocessed. On top of the standard, patients generate $1.5-2 \mathrm{~kg}$ of waste per day irrespective of the wards governed by the bed occupancy. On a regular day almost $75 \%$ of hospital beds are occupied by patients ${ }^{(9,10)}$. To administer up with this issue cordially suitable separation and disposable of (BMW) is essential and necessities to be done at the grassroot level. The healthiness concerns considerable to mal handling of this waste have been bring to notice regularly by the electronic media. On other hand, the establishment still hasn't been able to chalk-out way to accomplish with remaining to the latest challenges in the cities. The inflexibility lies in completion of the recent practices is essential to the non accessibility of resources and incomplete understanding associated to the health hazards related with it.

In developing countries similar to Pakistan regarding the knowledge of hospital waste management in terms of its separation, compilation, storage space, transportation and dumping is lacking, but in our country, each hospital must fulfill with the waste management rules 2005 Environment Protection Act 1997 of the organization of Pakistan. It also makes sure its level of service and waste management organization according to international standards ${ }^{(11-13)}$. The reason of this study was to find out the awareness, attitude and behavior regarding biomedical waste management regarding undergraduate dental student and house officers. 


\section{Materials And Methods:-}

This was a cross-sectional questionnaire based survey study conducted in September 2018-February 2019. The third and final year dental students were targeted population in this study. The self-structured questionnaire were made before and administered to the targeted people. Questionnaire was taken from different sources of research articles.

The survey was consisted of 2 parts. The first part of the survey form was contained of personal and professional data involving age, gender, qualification, experience and group of the practice. The second part was enclosed with 18 questions based on evaluation knowledge, attitude and practice about biomedical waste management. The entire questions in the questionnaire were closed- ended. The team of dental surgeons has distributed the questionnaires to the $3^{\text {rd }}$ year, $4^{\text {th }}$ year dental students and trainee house surgeons respectively.

Ethical review board:-

The informed consent was taken from ethical review board of the university as well as the study participants and they were requested to submit the questionnaire instantly.

\section{Statistical Analyzes:-}

By using the SPSS version of 17 software the result of this study was coded and analyzed as number and percentage of responders.

\section{Results:-}

A total of 150 BDS students (third and final year) and house surgeon were included, 55 students from $3^{\text {rd }}$ year, 68 students from final year and 27 house surgeon (1.81 mean, 2.459 std. deviation) that this included 88 male and 66 female participants (mean of 1.44 and std. deviation of 0.498). The knowledge, attitude and practice of students and house surgeons were assessed in this study.

Regarding the first and third part of the study the knowledge and practice of biomedical waste management should be discussed in table 1 and 2.

The second part of the study, $60.7 \%$ person's had a positive feedback about the biomedical waste should be segregated into different categories and most of the respondents gave no answer about the segregation of waste management is $39.3 \%$. The $53.3 \%$ participants concerning the biomedical waste management would be made a part of curriculum at undergraduate level; but the $44 \%$ people thinking about this management of biomedical waste should not integrated as a part of course curriculum at undergraduate level. Some study participants gave positive responses related to the requirement of teaching program of biomedical waste management for the awareness of public as well as doctors while mostly participants gave negative responses about the training of the biomedical waste they thinking that the BMWM program were not effective in students, doctors and staff members of the hospital. Concerning the responses of the study participants about the daily cleaning of dental suction were 54.7\%, some persons thinking that the cleaning of dental suction were twice in a week was $42.7 \%$ and about $2 \%$ individuals opinion were regarding the cleaning purpose of dental suction should be in a once a week but few participants was answered that the cleaning of dental suction was once a month.

Table 1:- Knowledge Assessment On Biomedical Waste Management

\begin{tabular}{|l|l|l|l|}
\hline S.No. & Questions & Yes (\%) & No (\%) \\
\hline 1. & Are you aware of the term healthcare waste? & $88(58.7 \%)$ & $62(41.3 \%)$ \\
\hline 2. & $\begin{array}{l}\text { Are you aware that health care waste management guidelines } \\
\text { are applicable to professionals? }\end{array}$ & $93(63 \%)$ & $57(38 \%)$ \\
\hline 3. & Do you know that all health care wastes are hazardous? & $78(52 \%)$ & $72(48 \%)$ \\
\hline 4. & Do you know about clinical waste management process? & $64(42.7 \%)$ & $86(52.3 \%)$ \\
\hline 5. & Do you know about color coding for waste separation? & $69(46 \%)$ & $81(54 \%)$ \\
\hline 6. & $\begin{array}{l}\text { Do you know that institute has standard storage room for } \\
\text { keeping hospital infectious waste? }\end{array}$ & $69(46 \%)$ & $81(54 \%)$ \\
\hline $\begin{array}{l}\text { According to healthcare waste management and handling guidelines } \\
\text { waste should not be stored beyond? }\end{array}$ & FREQUENCY (\%) \\
\hline
\end{tabular}




\begin{tabular}{|l|l|}
\hline 12 HOURS & $63(42 \%)$ \\
\hline 24 HOURS & $72(48 \%)$ \\
\hline 36 HOURS & $8(5.3 \%)$ \\
\hline I DON'T KNOW & $7(4.7 \%)$ \\
\hline
\end{tabular}

Table 2:- Practice Assessment On Biomedical Waste Management

\begin{tabular}{|l|l|l|l|}
\hline S.No. & Questions & Yes $(\%)$ & No (\%) \\
\hline 2. & Do you segregate general waste from clinical waste? & $76(50.7 \%)$ & $74(49.3 \%)$ \\
\hline 3. & $\begin{array}{l}\mid \\
\text { Do needles and sharp injuries need to be reported? think wearing personal protective equipment is } \\
\text { necessary? }\end{array}$ & $81(54 \%)$ & $63(42 \%)$ \\
\hline 4. & $\begin{array}{l}\text { Where do you dispose pharmaceutical, sharp cotton gauze waste and other items contraindicated } \\
\text { by blood? }\end{array}$ & $71(47.3 \%)$ \\
\hline & ONCE A MONTH & $69(46 \%)$ \\
\hline & ONCE A WEAK & $7(4.7 \%)$ \\
\hline & TWICE A WEAK & $2(1.3 \%)$ \\
\hline & $\begin{array}{l}\text { DAILY you dispose the hazardous liquid waste in which color coded } \\
\text { container or bag? }\end{array}$ & $61(40.7 \%)$ \\
\hline & RED PLASTIC & $61(40.7 \%)$ \\
\hline & YELLOW PLASTIC BAG & $28(18.7 \%)$ \\
\hline
\end{tabular}

\section{Discussion:-}

Bio Medical Waste management was a large significance due to its probable environmental and community health problems. The unsuitable disposal of waste imposes severe complications to the atmosphere as well as residential areas. The outbreak of disease may cause due to uncovered waste and can also pollute the water and soil, so this polluted water may be found at an extreme distance causing contagious diseases ${ }^{(13-14)}$.

In developing and underdeveloped countries, previous studies results shows that the Bio-medical Management of Waste was frequently varied with metropolitan solid waste and frequently disposed residential waste landfills mainly. Now a days advancement in the knowledge have been made to manage Bio medical Waste management in a proper way by waste generator along with ecological regulatory agencies ${ }^{(15)}$.

According to the World Health Organization fact sheet, about $20 \%$ of waste generated by different health care units is reported to be harmful. ${ }^{(16)}$ Quick urbanization and populace growth has led to more and additional number of hospitals and private clinics. All over the increase in health care services move toward the generation of excess amount of biomedical waste and additionally severe condition in future may be happening due to the toxicity and unavailability of dumping grounds for such wastes. ${ }^{(17)}$

In this study there is a plenty of information available concerning the awareness of health concern waste. Some dental professional students have fine knowledge about guidelines of health concern waste management and the majority of the dental students had good awareness regarding the biomedical waste was hazardous. Concerning about the clinical process of waste management, color coding for the separation of waste and infectious waste for dental hospital have fair understanding regarding the BMWM. Awareness regarding healthcare waste management and handling guidelines waste among dental students and trainee house surgeons was $42 \%$ should not be stored beyond 12 hours but $48 \%$ study participants thinks regarding the handling of health-care waste management shouldn't be stored beyond 24 hours.

Regarding the World Health Organization hospital waste yields 80 to $85 \%$ of nonhazardous waste and 15 to $20 \%$ of hazardous waste. The hazardous waste can be infectious (10\%) like sharps or noninfectious (5\%), such as chemical 
and pharmaceutical waste. ${ }^{(18)}$ Dental doctors were at a high risk for cross-infection whilst treating the patients, as most pathogens have been isolated from saliva. ${ }^{(19-20)}$

There was a basic need to educate health care personnel regarding activities of Bio-Medical Waste management. Many of the studies reported that healthcare personnel have knowledge regarding BMW management but it has not put being practiced. Few literatures mentioned that knowledge of BMW management among students is not appropriate. It is very important to improve the skills, attitude of Bio medical waste management and encourage students to put into practice.

Another study was done in Indian Health care professionals who handle waste were at high chance of getting life threatening diseases like hepatitis B and C and HIV by infected needles and other sharp waste. For this reason, the knowledge regarding various hazards of needle stick injury is necessary among health care providers. It reveals that almost all the participants (96\%) were aware about the hazards of needle stick injury and comparison with the study done by another researcher on awareness of BMW management among health care staff in Jaipur India shows very poor knowledge about these. ${ }^{(21)}$ In this present study, regarding the needle and sharp injuries were reported at $58 \%$, however the $42 \%$ respondents reported that they do not observe the sharp-needle injuries. Some dental professional students had practicing about the segregation of biomedical waste management in different color coding bags should be report at $40.7 \%$ red and yellow plastic bags but $18.7 \%$ students were thinking regarding the disposal of waste in blue bags. Another research study reports that, it was observed that only $25 \%$ hospitals were segregated sharps, pathological waste, chemical, infectious, pharmaceutical and under pressure containers at source. ${ }^{(22)}$

The 54\% students were thinking about the wearing of using personal protective equipment was necessary to wear during dental treatment in their clinical sessions. About $46 \%$ students have no thoughts concerning about the wearing of personal protective equipments. This was observed in this present study.

So that the result of the current study would recommend that appropriate waste management instructive syllabus would be integrated in the national program of study for dental education, so as to give importance to this hazardous problem. Bio-Medical Waste organization cannot be achieved effectively without the successful knowledge, enthusiasm, education, and cooperation from all the dental students, trainee dental surgeons and as well as healthcare Professionals.

\section{Conclusion:-}

In present study showed to facilitate the information and level of awareness of the study subjects was not sufficient and there was a significant difference put into practice and management about the biomedical waste management amongst different studies. In protected hands and effective dumping of waste was not only an authorized requirement although there was also a common responsibility. Ongoing learning and education programmes as well as course on cross-infection and biomedical waste management were appropriate resources to improve the familiarity of dental students. Consequently the biomedical waste organization should be firmly implemented and monitored in a systemic and basic approach through reliable bodies in under-developed and developing countries. The government must also take the task to bring the information regarding biomedical waste management to the dentist, dental students and also in medical hospitals.

\section{Conflict of intrest:-}

Authors declared no conflict of interest.

\section{References:-}

1. Das SK, Biswas R. Awareness and practice of biomedical waste management among healthcare providers in a Tertiary Care Hospital of West Bengal, India. International Journal of Medicine and Public Health. 2016;6(1).

2. Basu M, Das P, Pal R. Assessment of future physicians on biomedical waste management in a tertiary care hospital of West Bengal. Journal of natural science, biology, and medicine. 2012 Jan;3(1):38.

3. Kalpana V.N., Prabhu D.S, Vinodhini S., Devirajeswari V. Biomedical waste and its management. J. Chem.Pharm.Res., (2016) 8(4): 670-676.

4. Kumar M, Kumari M, Singh G, Kumari R. Knowledge, Awareness and Attitude regarding Biomedical Waste Management among Medical Students in a tertiary health Care centre: A Cross Sectional Study. Indian J Med Res [serie en internet]. 2017 Apr:611-4. 
5. Sudeep CB, Joseph J, Chaitra T, Joselin J, Nithin P, Jose J. KAP study to assess biomedical waste management in a dental college in south India. World J Pharm Pharm Sci. 2017 Feb 9;6:1788-94.

6. Mehta TK, Shah PD, Tiwari KD. A Knowledge, Attitude and Practice Study of Biomedical Waste Management and Bio-safety among Healthcare Workers in a Tertiary Care Government Hospital in Western India. Community Med. 2018;9(5):327-33.

7. Soyam GC, Hiwarkar PA, Kawalkar UG, Soyam VC, Gupta VK. KAP study of bio-medical waste management among health care workers in Delhi. International Journal Of Community Medicine And Public Health. 2017 Aug 23;4(9):3332-7.

8. Soriano V, Barreiro P, Nuñez M. Management of chronic hepatitis B and C in HIV-coinfected patients. Journal of Antimicrobial Chemotherapy. 2006 May 1;57(5):815-8.

9. Ali S, Mahmood U, Malik AU, Aziz F, Naghman RB, Ahmed I. Current hospital waste management practices in Pakistan: case study and curative measures. Public Health Prevent Med. 2015 Aug;1(3):125-9.

10. Mathur P, Patan S, Shobhawat AS. Need of biomedical waste management system in hospitals-An emerging issue-a review. Current World Environment. 2012;7(1):117.

11. Sapkota B, Gupta GK, Mainali D. Impact of intervention on healthcare waste management practices in a tertiary care governmental hospital of Nepal. BMC public health. 2014 Dec;14(1):1005.

12. Hassan MM, Ahmed SA, Rahman KA, Biswas TK. Pattern of medical waste management: existing scenario in Dhaka City, Bangladesh. BMC Public Health. 2008 Dec;8(1):36.

13. Abah SO, Ohimain EI. Healthcare waste management in Nigeria: A case study. Journal of Public health and Epidemiology. 2011 Mar 31;3(3):99-110.

14. Abdulla F, Qdais HA, Rabi A. Site investigation on medical waste management practices in northern Jordan. Waste management. 2008 Jan 1;28(2):450-8.

15. Askarian M, Vakili M, Kabir G. Results of a hospital waste survey in private hospitals in Fars province, Iran. Waste management. 2004 Jan 1;24(4):347-52.

16. Pandit NB, Mehta HK, Kartha GP, Choudhary SK. Management of bio-medical waste: Awareness and practices in a district of Gujarat. Indian J Public Health. 2005 Oct 1;49(4):245-7.

17. Vilas MA. A critical overview of legal profile on solid waste management in India. International Journal of Research in Chemistry and environment. 2015 Jan;5(1):1-6.

18. Singh RD, Jurel SK, Tripathi S, Agrawal KK, Kumari R. Mercury and other biomedical waste management practices among dental practitioners in India. BioMed Research International. 2014;2014.

19. Singh BP, Khan SA, Agrawal N, Siddharth R, Kumar L. Current biomedical waste management practices and cross-infection control procedures of dentists in India. International dental journal. 2012 Jun;62(3):111-6.

20. Pandit NB, Mehta HK, Kartha GP, Choudhary SK. Management of bio-medical waste: Awareness and practices in a district of Gujarat. Indian J Public Health. 2005 Oct 1;49(4):245-7.

21. Sharma A, Sharma V, Sharma S, Singh P. Awareness of biomedical waste management among health care personnel in Jaipur, India. Oral Health Dent Manag. 2013 Mar;12(1):32-40.

22. Sham Sundar SD, Chetan BB, Gopinath D. Knowledge, Attitude, and Practice of Universal Precautions and Occupational Safety among nursing professionals in tertiary centers in Bangalore. Journal of ISHWM. 2006 Apr;5(1):27-30. 